Rev. Bras. Saúde Prod. Anim., Salvador, v.16, n.3, p.582-590 jul./set.., 2015 http://www.rbspa.ufba.br

\title{
Desempenho e rendimento de carcaça de suínos na fase de terminação, recebendo dietas com diferentes níveis de ractopamina
}

\author{
Performance and carcass yield of pig fed diets containing different levels of \\ ractopamine
}

\author{
LEAL, Renato Silva ${ }^{1}$; MATTOS, Bruno Olivetti de $^{2 *}$; CANTARELLI, Vinícius de \\ Souza $^{2}$; CARVALHO, Guilherme Cleto de ${ }^{1}$; PIMENTA, Maria Emília de Sousa \\ Gomes ${ }^{1}$; PIMENTA, Carlos José ${ }^{3}$
}

\footnotetext{
${ }^{1}$ Universidade Federal de Lavras, Programa de Pós-Graduação em Ciências Veterinárias, Lavras, Minas Gerais, Brasil.

${ }^{2}$ Universidade Federal de Lavras, Programa de Pós-Graduação em Zootecnia, Lavras, Minas Gerais, Brasil.

${ }^{3}$ Universidade Federal de Lavras, Departamento de Ciência dos Alimentos, Lavras, Minas Gerais, Brasil.

*Endereço para correspondência: mattos.bo@gmail.com
}

\section{RESUMO}

O objetivo com este trabalho foi avaliar o desempenho e o rendimento de carcaça de suínos na fase de terminação de machos castrados e fêmeas, recebendo dietas contendo diferentes níveis de ractopamina. Foram utilizados 60 animais, com peso inicial de 84,27 $\pm 2,26 \mathrm{~kg}$, aleatoriamente distribuídos para uma das seis dietas experimentais compostas por diferentes níveis de ractopamina (zero; três; seis; nove; 12 e $15 \mathrm{ppm}$ ) e cinco repetições por tratamento. Ao final do período experimental, foi avaliado o efeito dos diferentes níveis de ractopamina sobre o peso final (PF), consumo de ração médio diário (CRMD), ganho de peso médio diário (GPMD), conversão alimentar (CA) e rendimento de carcaça. Observou-se aumento linear $(\mathrm{P}<0,05)$ para peso final e ganho de peso médio diário, à medida que houve aumento dos níveis de ractopamina. Para a conversão alimentar $(\mathrm{P}<0,05)$, evidenciou-se decréscimo de $25,50 \%$ nos animais que receberam $15 \mathrm{ppm}$ de ractopamina na dieta. Para o consumo de ração médio diário e rendimento de carcaça, não foram observados efeitos significativos $(\mathrm{P}>0,05)$. A adição de ractopamina na dieta de suínos machos castrados e fêmeas em terminação proporcionou melhor desempenho aos animais, promovendo melhoras nos parâmetros produtivos.

Palavras-chave: agonista $\beta$-adrenérgico, produtividade animal, produção de carne

\section{SUMMARY}

The objective of this study was to evaluate the performance and carcass yield of finishing castrated males and females pigs, supplemented with diets containing different levels of ractopamine. Sixty animals were used, with initial body weight of $84.27 \pm 2.26 \mathrm{~kg}$, distributed in a randomized block design, consisting of six levels of ractopamine $(0 ; 3 ; 6$; $9 ; 12$ and $15 \mathrm{ppm}$ ) and five repetitions per treatment. At the end of the trial period, it was evaluated the effect of different levels of ractopamine on the final body weight (FW), average daily feed intake (ADFI), average daily weight gain (ADG), feed conversion (FC) and carcass yield. It was observed a linear increase $(\mathrm{P}<0,05)$ in the levels of ractopamine for final weight, as well as for the average daily weight gain. For feed conversion $(\mathrm{P}<0,05)$, it was evident a decrease of $25.50 \%$ in animals supplemented with $15 \mathrm{ppm}$ of ractopamine in the diet. For average daily feed intake and carcass yield there was no significant effect $(\mathrm{P}>0,05)$. The supplementation with ractopamine in the diet of finishing castrated males and females pigs, provides greater performance to the animals, improving production yield.

Keywords: beta-adrenergic agonist animal, meat production, productivity 
Rev. Bras. Saúde Prod. Anim., Salvador, v.16, n.3, p.582-590 jul./set.., 2015 http://www.rbspa.ufba.br ISSN 15199940

\section{INTRODUÇÃO}

No ciclo de produção de suínos, a fase de terminação é a que apresenta maior transformação na composição da carcaça e, ao mesmo tempo, pior conversão alimentar, sendo necessário um aumento no consumo de ração para produzir um quilo de carne (CANTARELI et al., 2009).

Neste contexto, de uso de substâncias que melhoram o desempenho produtivo, estão presentes a suplementação de aminoácidos essenciais, vitaminas e repartidores de nutrientes. Dentre estas substâncias, a ractopamina é um agonista $\beta$-adrenérgico sintético, comprovadamente eficiente na produção de carne, de menor deposição de tecido adiposo e maior porcentagem de carne magra na carcaça dos suínos (CANTARELI et al., 2009).

A ractopamina atua em vias metabólicas específicas, especialmente nos metabolismos protéico, lipídico e de carboidratos, ativando o aumento da taxa de lipólise devido à ação de enzima proteína quinase A (PKA). A sua ativação também apresenta participação das proteínas $\mathrm{G}$, que ativam a adenilciclase, convertendo adenosina trifosfato em adenosina monofosfato. $\mathrm{O}$ adenosina monofosfato atua como finalizador intracelular, ligando-se à subunidade da PKA, ativando-a e levando à fosforilação de muitas enzimas, elevando a taxa de lipólise (MOODY et al., 2000) e favorecendo a síntese protéica em detrimento da deposição de tecido adiposo na carcaça (WATKINS et al., 1990; GUNAWAN et al., 2007).

Vários trabalhos indicam que as modificações metabólicas proporcionadas pela utilização da ractopamina na dieta melhoram de forma significativa o desempenho desses animais (ARMSTRONG et al. 2004; BRIDI et al., 2008; KIEFER \& SANCHES, 2009; SANCHES et al., 2010a, FERREIRA et al., 2011), além de proporcionar redução na espessura de toucinho e aumento na porcentagem de carne magra e rendimento de carcaça (KIEFER \& SANCHES, 2009).

Em grande parte das pesquisas realizadas, até o momento, com suínos, os níveis de ractopamina utilizados situam-se entre cinco e $20 \mathrm{ppm}$, com níveis variando a cada cinco unidades (STOLLER et al. 2003; ARMSTRONG et al. 2004; WEBER et al., 2006; BRIDI et al., 2008; CANTARELI et al., 2009; KIEFER \& SANCHES, 2009; SANCHES et al., 2010a; FERREIRA et al., 2011), o que causa algumas discrepâncias nos resultados, que vão desde um maior ganho de peso, menor consumo de ração, maior rendimento de carcaça e melhor conversão alimentar, até uma ausência total de efeitos.

Torna-se necessário, portanto, fracionar os níveis já listados, cinco a 20ppm, sobretudo no intervalo de cinco a $15 \mathrm{ppm}$, em que a ractopamina mostrouse mais eficiente.

O trabalho teve como objetivo avaliar o desempenho e o rendimento de carcaça de suínos recebendo dietas com níveis crescentes de ractopamina compreendidos entre zero e $15 \mathrm{ppm}$, na fase de terminação, por um período de 28 dias.

\section{MATERIAL E MÉTODOS}

Foram utilizados 60 animais, sendo 30 suínos machos castrados e 30 fêmeas, híbridos (fêmea C40 X reprodutor TopPi), selecionados para alto ganho de tecido magro, com peso inicial de 84,27 $\pm 2,26 \mathrm{~kg}$. Estes foram alojados em um galpão de terminação em baias de piso 
Rev. Bras. Saúde Prod. Anim., Salvador, v.16, n.3, p.582-590 jul./set.., 2015 http://www.rbspa.ufba.br ISSN 15199940

de concreto $(2,3 \mathrm{~m} \times 1,5 \mathrm{~m})$, dotadas de comedouros semiautomáticos e bebedouros tipo chupeta, sendo dois animais (um macho castrado e uma fêmea) por baia, recebendo dietas e água a vontade. A temperatura média no galpão foi de $23 \pm 2{ }^{\circ} \mathrm{C}$.

As dietas isoprotéicas e isoenergéticas experimentais foram formuladas à base de milho e farelo de soja, suplementadas com vitaminas, minerais e aminoácidos, de forma a atender às exigências sugeridas pela linhagem (NRC, 2000), com um acréscimo de $30 \%$ nos níveis de lisina, em função da maior taxa de síntese protéica em animais suplementados com ractopamina (XIAO et al., 1999) (Tabela $1)$.

Tabela 1. Composição centesimal e valores calculados das dietas experimentais

\begin{tabular}{|c|c|c|c|c|c|c|}
\hline \multirow{2}{*}{ Ingredientes $(\%)$} & \multicolumn{6}{|c|}{ Níveis de ractopamina (ppm) } \\
\hline & 0 & 3 & 6 & 9 & 12 & 15 \\
\hline Milho & 71,660 & 71,660 & 71,660 & 71,660 & 71,660 & 71,660 \\
\hline Farelo de soja & 23,700 & 23,700 & 23,700 & 23,700 & 23,700 & 23,700 \\
\hline Óleo de soja & 1,840 & 1,840 & 1,840 & 1,840 & 1,840 & 1,840 \\
\hline Fosfato Bicálcico & 1,080 & 1,080 & 1,080 & 1,080 & 1,080 & 1,080 \\
\hline Calcário Cálcitico & 0,800 & 0,800 & 0,800 & 0,800 & 0,800 & 0,800 \\
\hline Sal & 0,360 & 0,360 & 0,360 & 0,360 & 0,360 & 0,360 \\
\hline Premix Mineral $^{1}$ & 0,050 & 0,050 & 0,050 & 0,050 & 0,050 & 0,050 \\
\hline Premix vitamínico $^{2}$ & 0,100 & 0,100 & 0,100 & 0,100 & 0,100 & 0,100 \\
\hline DL-Metionina $99 \%$ & 0,020 & 0,020 & 0,020 & 0,020 & 0,020 & 0,020 \\
\hline L-Lisina $78 \%$ & 0,260 & 0,260 & 0,260 & 0,260 & 0,260 & 0,260 \\
\hline L-Treonina 98\% & 0,110 & 0,110 & 0,110 & 0,110 & 0,110 & 0,110 \\
\hline Tylan ${ }^{3}$ & 0,020 & 0,020 & 0,020 & 0,020 & 0,020 & 0,020 \\
\hline \multirow[t]{2}{*}{ Cloridrato de ractopamina $2,05 \%$} & 0,000 & 0,015 & 0,030 & 0,045 & 0,060 & 0,075 \\
\hline & \multicolumn{6}{|c|}{ Composição calculada } \\
\hline Proteína bruta $(\%)$ & 16,060 & 16,060 & 16,060 & 16,060 & 16,060 & 16,060 \\
\hline $\mathrm{EM}(\mathrm{Kcal} / \mathrm{Kg})$ & 3300 & 3300 & 3300 & 3300 & 3300 & 3300 \\
\hline Lisina digestível (\%) & 1,002 & 1,002 & 1,002 & 1,002 & 1,002 & 1,002 \\
\hline Metionina digestível (\%) & 0,267 & 0,267 & 0,267 & 0,267 & 0,267 & 0,267 \\
\hline Treonina digestível $(\%)$ & 0,661 & 0,661 & 0,661 & 0,661 & 0,661 & 0,661 \\
\hline Fósforo disponível (\%) & 0,300 & 0,300 & 0,300 & 0,300 & 0,300 & 0,300 \\
\hline Cálcio $(\%)$ & 0,647 & 0,647 & 0,647 & 0,647 & 0,647 & 0,647 \\
\hline
\end{tabular}

${ }^{\mathrm{I}}$ Composição, por kg de produto: cálcio, $98.800 \mathrm{mg}$; cobalto, $185.0 \mathrm{mg}$; cobre, $15.750 \mathrm{mg}$; ferro, $26.250 \mathrm{mg}$; iodo, $1.470 \mathrm{mg}$; zinco, $77.999 \mathrm{mg}$.

${ }^{2}$ Composição, por kg de produto: ácido fólico, $116.55 \mathrm{mg}$; ácido pantotênico, $2.333 \mathrm{mg}$; biotina, $5.28 \mathrm{mg}$; niacina, $5.600 \mathrm{mg}$; piridoxina, $175 \mathrm{mg}$; riboflavina, $933,3 \mathrm{mg}$; tiamina $175 \mathrm{mg}$; vitamina A, 1.225 .000 U.I.; vitamina D3, 315.000 U.I.; vitamina E, $1.400 \mathrm{mg}$; vitamina K3, 700mg; vitamina B12, $6.825 \mathrm{mg}$; selênio, $105 \mathrm{mg}$; antioxidante, $1.500 \mathrm{mg}$.

${ }^{3}$ Antibiótico à base de tilosina granulada.

Ao final do período experimental, os animais foram pesados, e o consumo e as sobras de ração foram mensurados para as avaliações de desempenho. Após jejum de 12 horas, todos os animais foram novamente pesados em balança digital marca Weightech modelo WT 3000-T e abatidos por dessenssibilização elétrica, seguida de sangria e evisceração.

A unidade experimental foi de dois animais (um macho castrado e uma fêmea) por baia, sendo a ração e água fornecidos à vontade. $\mathrm{O}$ delineamento experimental foi em blocos casualizados (época de entrada dos animais no 
Rev. Bras. Saúde Prod. Anim., Salvador, v.16, n.3, p.582-590 jul./set.., 2015 http://www.rbspa.ufba.br ISSN 15199940

experimento), com seis tratamentos (níveis de zero, três, seis, nove, 12 e 15 ppm de ractopamina) e cinco repetições por tratamento.

Os níveis de ractopamina na alimentação e o sexo dos animais foram avaliados pelos seguintes parâmetros: o efeito dos diferentes níveis de ractopamina sobre o peso final (PF), o consumo de ração médio diário (CRMD), o ganho de peso médio diário (GPMD), a conversão alimentar (CA) e o rendimento de carcaça.

Os dados obtidos foram submetidos à ANOVA de acordo com o seguinte modelo estatístico:

Resposta $=\mathrm{PI}+\mathrm{S}+\mathrm{R}+(\mathrm{S} \times \mathrm{R})+$ erro, onde:

PI é o peso inicial e representa o efeito da classe de peso ou do peso em si, por uma correção linear do peso inicial nas respostas observadas por análise de covariância. Os termos com sexo (S) e ractopamina $(\mathrm{R})$ representam os efeitos dos fatores já descritos e sua interação. $\mathrm{O}$ termo de erro associa uma distribuição normal, com erros independentes e de mesma variância (pressupostos da análise de (co)variância).

Foram avaliados, os dados, e submetidos à análise de variâncias cujo acordo pressuposto foi verificado por inspeção, visualização e aplicação dos testes Shapiro-Wilk (para normalidade) e Hartlet (para homocedasticidade). Para interações significativas, foi estudado o efeito de ractopamina em cada sexo. $\mathrm{O}$ efeito de sexo foi comparado pelo teste $\mathrm{F}$ da análise de variância. Todas as inferências foram aplicadas ao nível nominal de significância de 5\%. O estudo dos efeitos, como comparações de médias e predições com os modelos de regressão, foi efetuado com o modelo reduzido. As análises foram realizadas utilizando $o$ programa computacional R Development Core Team (2010).
Adicionalmente, para a avaliação das variáveis de peso final e ganho de peso médio diário, foi utilizada regressão descontínua linear response plateau (LRP) para estimação do nível ótimo de ractopamina. Esta análise foi realizada por meio do software SAEG versão 9.1 (UFV, 2007).

O estudo foi aprovado pela Comissão de Ética no Uso de Animais n. 004/2010.

\section{RESULTADOS E DISCUSSÃO}

Não se observou interação de sexo $(\mathrm{P}>0,05)$ com ractopamina, nem efeito de sexo. Os contrastes do nível zero de ractopamina contra os demais foram significativamente diferentes de zero $(\mathrm{P}<0,05)$, nos quais se comprovou a influência da ractopamina no peso final dos animais suplementados com rações com esse aditivo, este efeito corrobora Garbossa et al. (2013), que verificaram o efeito linear em animais suplementados com ractopamina. Da mesma forma que Carr et al. (2009), testando níveis de zero, cinco e 10 ppm de ractopamina, observaram peso médio final de $133 \mathrm{~kg}$, e Moore et al. (2009), comprovaram um aumento de peso em animais suplementados com ractopamina quando comparados ao grupo controle.

Foi constatado efeito linear $(\mathrm{P}<0,05)$ dos níveis de ractopamina sobre o peso final dos suínos $(\mathrm{PF}=108,703+$ 0,422rac). Espera-se um aumento de $0,422 \mathrm{~kg}$ para cada um ppm de ractopamina na ração, quando essa é fornecida até $15 \mathrm{ppm}$, sendo que, os animais que receberam a dieta contendo $15 \mathrm{ppm}$ de ractopamina apresentaram peso final 5,83\% superior em relação ao animais que receberam a dieta sem adição de ractopamina (Tabela 2). Marinho et al. (2007a), suplementando rações para suínos contendo 
Rev. Bras. Saúde Prod. Anim., Salvador, v.16, n.3, p.582-590 jul./set.., 2015 http://www.rbspa.ufba.br ISSN 15199940

ractopamina, nos níveis zero e cinco ppm, observaram aumento de $3 \%$ no peso final em relação a dieta controle.

$\mathrm{O}$ ajuste do modelo LRP para o peso final indicou que a dose mínima de ractopamina para propiciar um maior peso final foi de $13,14 \mathrm{ppm}$, resultando em um valor de $114,23 \mathrm{~kg}$.

Garbossa (2013) observou efeito linear para o peso final, sendo que animais recebendo dietas suplementados com $20 \mathrm{ppm}$ de ractopamina apresentaram peso superior.

Armstrong et al. (2004), fornecendo os níveis de ractopamina zero, cinco, $10 \mathrm{e}$ 20ppm por diferentes números de dias (seis; 13; 20; 27 e 34 dias de fornecimento das dietas experimentais), observaram que nos últimos 27 dias de terminação os pesos finais das carcaças que receberam dietas suplementadas com cinco, 10 ou 20ppm de ractopamina foram semelhantes entre si e superiores àqueles que receberam a dieta controle.

Carr et al. (2005), testando diferentes níveis de ractopamina (zero, $10 \mathrm{e}$ $20 \mathrm{ppm})$ também por tempos diferentes $(25 ; 27 ; 32 ; 34$ e 39 dias), observaram que os suínos que receberam os níveis de 10 e 20ppm apresentaram-se mais pesados ao final do experimento, em relação ao controle, e que o nível de 20 ppm apresentou o melhor resultado.

Ferreira et al. (2011) evidenciaram aumento no peso final dos suínos recebendo dietas com ractopamina nos níveis cinco, 10; 15 e 20ppm, em relação ao controle. Ao mesmo tempo, observaram que doses superiores a cinco ppm de ractopamina não apresentaram benefícios adicionais. Outros autores não encontraram efeito da adição de ractopamina na dieta. Pereira et al. (2008), trabalhando com adição da ractopamina (zero e cinco ppm) e dois níveis de lisina digestível (0,67 e 0,87\%) na dieta fornecida por tempos diferentes,
21 e 28 dias, não evidenciaram resposta nesses períodos estudados. Sanches et al. (2010a), avaliando suínos machos castrados em terminação, recebendo os níveis de zero, cinco, 10 e 20ppm de ractopamina, não verificaram efeito sobre o peso final. Mimbs et al. (2005), utilizando até $10 \mathrm{ppm}$ de ractopamina para suínos em terminação, não observaram diferença no peso final.

Com relação ao ganho de peso médio diário (GPMD), observou-se efeito linear $(\mathrm{GMPD}=0,871+0,015 \mathrm{rac}$ ) esperando-se um aumento de $0,0151 \mathrm{~kg} / \mathrm{dia}$ no ganho de peso para cada um ppm de ractopamina na ração, quando essa é fornecida até 15ppm; considerando-se o nível de $15 \mathrm{ppm}$, comparado ao controle, foi verificado aumento de $25,29 \%$ no ganho de peso dos animais. Os contrastes do nível zero de ractopamina contra os demais foram significativamente diferentes de zero, nos quais se comprovou a influência da ractopamina no ganho de peso médio diário dos animais suplementados com rações contendo esse aditivo (Tabela 2). O aumento da síntese protéica, em detrimento da lipogênese, resulta em uma alteração da composição do ganho, ou seja, os animais depositam mais proteína e menos gordura. O direcionamento de nutrientes para a deposição de tecido magro promove a maior retenção de água, proporcional à quantidade de ractopamina fornecida.

No ajuste do modelo LRP, apontou-se que a dose mínima de ractopamina para fornecer um maior ganho de peso foi de $12,96 \mathrm{ppm}$ para ganho de peso médio diário, resultando em um valor de $1,06 \mathrm{~kg} /$ dia.

Com relação ao ganho de peso médio diário, Garbossa (2013) observou efeito linear da ractopamina, evidenciando um incremento de $18,87 \%$ no ganho dos animais, quando utilizaram 20ppm deste aditivo na dieta. 
Rev. Bras. Saúde Prod. Anim., Salvador, v.16, n.3, p.582-590 jul./set.., 2015 http://www.rbspa.ufba.br ISSN 15199940

Em contrapartida, de acordo com os trabalhos de Pereira et al. (2008), os quais testaram o efeito da ractopamina nos níveis zero e cinco ppm e de dois níveis de lisina digestível $(0,67 \%$ e $0,87 \%$ ) na dieta, não foi observada influência da ractopamina no ganho de peso dos animais.
Sanches et al. (2010a; 2010b), testando níveis de ractopamina (zero; cinco; 10 e 20 ppm) em suínos castrados em terminação, mantidos sob estresse por calor e sob conforto térmico, respectivamente, por um período de 28 dias, constataram aumento linear no ganho de peso médio diário.

Tabela 2. Desempenho de suínos em terminação, alimentados com diferentes níveis de ractopamina (zero, três, seis, nove, 12 e 15 ppm) durante 28 dias

\begin{tabular}{lccccccc}
\hline \multirow{2}{*}{ Variável } & \multicolumn{7}{c}{ Doses de ractopamina (ppm) } \\
\cline { 2 - 8 } & 0 & 3 & 6 & 9 & 12 & 15 & $\begin{array}{l}\text { CV } \\
(\%)\end{array}$ \\
\hline $\begin{array}{l}\text { Peso Inicial }(\mathrm{kg}) \\
\text { Peso final }^{1}(\mathrm{~kg})\end{array}$ & 84,15 & 84,20 & 84,20 & 84,25 & 84,30 & 84,50 & 2,68 \\
Ganho de peso médio diário $^{1}$ & 108,70 & 109,97 & 111,23 & 112,50 & 113,77 & 115,04 & 5,27 \\
(kg/dia) $_{\text {Consumo diário médio de ração }}$ & 0,87 & 0,92 & 0,96 & 1,01 & 1,05 & 1,09 & 5,07 \\
(kg/dia) $_{\text {Conversão alimentar }}^{1}$ & 2,79 & 2,92 & 2,66 & 2,90 & 2,88 & 2,78 & 7,98 \\
Rendimento de carcaça(\%) $^{1}$ & 3,33 & 3,17 & 3,01 & 2,84 & 2,68 & 2,52 & 6,32 \\
& 80,86 & 78,62 & 80,86 & 80,02 & 79,88 & 79,98 & 4,06 \\
\hline
\end{tabular}

${ }^{\mathrm{T}}$ Regressão linear significativa $(\mathrm{P}<0,05)$.

O consumo de ração médio diário (CRMD) não foi influenciado pelos níveis de ractopamina adicionados nas dietas. Bridi et al. (2008), Ferreira et al. (2011), Garbossa (2013) e Marinho et al. (2007b), estudando a ractopamina em dietas para suínos em terminação, também observaram que este aditivo não afetou o consumo.

$\mathrm{O}$ consumo de ração médio diário por suínos depende do nível energético da ração e, como todas as rações foram isocalóricas, já era esperado um consumo de ração médio diário semelhante. A ractopamina não aumenta a ingestão, e sim promove alterações metabólicas, com aumento da síntese protéica e bloqueio da lipogênese, que afetam diretamente outras variáveis de desempenho.

Quanto à conversão alimentar (CA), observou-se efeito linear positivo $(\mathrm{CA}=$ 3,033 - 0,054 rac), no qual, com o aumento de um ppm de ractopamina na dieta dos suínos, espera-se uma diminuição na conversão alimentar de 0,054 , quando essa for fornecida até 15 ppm. Considerando este, o nível 15ppm comparado ao controle, foi verificado redução de $24,54 \%$ na conversão alimentar.

Sanches et al. (2010a) também observaram efeito linear sobre a conversão alimentar, fornecendo ração com ractopamina nos níveis zero, cinco, 10, 15 e 20ppm. Marinho et al. $\left(2007^{\mathrm{a}}, \mathrm{b}\right)$ observaram melhora na conversão alimentar, suplementando ractopamina (zero e cinco ppm) na dieta de suínos machos castrados, em terminação.

Ferreira et al. (2011), Garbossa (2013) e Rossi et al. (2010), estudando efeito da ractopamina no desempenho de suínos, também observaram melhor conversão 
Rev. Bras. Saúde Prod. Anim., Salvador, v.16, n.3, p.582-590 jul./set.., 2015 http://www.rbspa.ufba.br ISSN 15199940

alimentar em suínos suplementados com ractopamina.

A ractopamina altera a composição do ganho, pois os animais depositam mais proteína e menos gordura. Aumentando a deposição protéica, aumenta-se o ganho de peso, uma vez que se agrega água. Além disso, a síntese de tecido muscular representa, metabolicamente, economia energética para o animal, quando comparado com a deposição de tecido adiposo. Melhorando a eficiência de utilização dos nutrientes, resulta em melhor conversão alimentar.

Em relação ao rendimento de carcaça (REC), não se evidenciou diferença significativa $(\mathrm{P}>0,05)$ entre o grupo controle e os níveis de ractopamina testados, e nem do sexo.

Bridi et al. (2008), Marinho et al. (2007a) e Sanches (2010a), estudando os níveis de ractopamina zero, cinco, 10 e 20ppm, para suínos machos castrados, em terminação, não constataram efeito da suplementação com ractopamina sobre o rendimento de carcaça. Apesar de influenciar o peso final e o ganho de peso médio diário, a ractopamina aumenta a porcentagem de carne, pois atua sobre o crescimento do músculo esquelético e não de outros órgãos. Sendo assim, o peso das vísceras é determinante nos valores obtidos para rendimento de carcaça.

Assim, confirma-se que a ractopamina é eficaz em melhorar o desempenho de suínos em terminação, machos castrados e fêmeas, uma vez que afeta positivamente o peso final e a conversão alimentar, à medida que aumenta de zero para $15 \mathrm{ppm}$.

\section{AGRADECIMENTOS}

Os autores deste trabalho agradecem ao Conselho Nacional de Desenvolvimento Cientifico e Tecnológico - CNPq, pelo financiamento desta pesquisa.

\section{REFERÊNCIAS}

ARMSTRONG, T.A.; IVERS, D.J.; WAGNER, J.R.; ANDERSON, D.B.; WELDON, W.C.; BERG, E.P. The effect of dietary ractopamina concentration and duration of feeding on growth performance, carcass characteristics and meat quality of finishing pig. Journal of Animal Science, v.82, n.11, p.32453253, 2004.

BRIDI, A.M.; OLIVEIRA, A.R.; FONSECA, N.A.; COUTINHO, L.L.; HOSHI, E.H.; BOROSKY, J.C.; SILVA, C.A. Effects of ractopamina and gender on performance and carcass quality of swine with different halothane genotypes. Ciências Agrárias, v.29, n.3, p.713-722, 2008.

CANTARELLI, V.S.; FIALHO, E.T.; ALMEIDA, E.C.; ZANGERONIMO, M.G.; AMARAL, N.O.; LIMA, J.A. F. Características da carcaça e viabilidade econômica do uso de cloridrato de ractopamina para suínos em terminação com alimentação à vontade ou restrita.

Ciência Rural, v.39, n.3, p.844-851, 2009.

CARR, S.N.; RINCKER, P.J.;

KILLEFER, J.; BAKER, D.H.; ELLIS, M.; MCKEITH, F.K. Effects of different cereal grains and ractopamine hydrochloride on performance, carcass characteristics, and fat quality in latefinishing pigs. Journal of Animal Science, v.83, v.1, p.223-230, 2005.

CARR, S.N.; HAMILTON, D.N.; MILLER, K.D.; SCHROEDER, A.L.; FERNÁNDEZ-DUEÑAS, D.M.; KILLEFER, J.; ELLIS, M.; McKEITH, F. K. The effect of ractopamine hydrochloride (Paylean) on lean carcass yields and pork quality characteristics of heavy pigs fed normal amino acid 
Rev. Bras. Saúde Prod. Anim., Salvador, v.16, n.3, p.582-590 jul./set.., 2015 http://www.rbspa.ufba.br ISSN 15199940 http://dx.doi.org/10.1590/S1519-99402015000300010

fortified diets. Meat Science, v.81, FERREIRA, M.S.S.; SOUSA, R.V.; SILVA, V.O.; ZANGERÔNIMO, M.G.; AMARAL, N.O. Cloridrato de ractopamina em dietas para suínos em terminação. Acta Scientiarum, Animal Sciences, v.33, n.1, p.25-32, 2011.

GARBOSSA, C.A.P.; CANTARELLI, V. de S.; SOUSA, R.V.; CANTARELLI, V.S.; PIMENTA, M.E.S.G.;

ZANGERONIMO, M.G.; SILVEIRA, H.; KURIBAYASHI, T.H.; CERQUEIRA, L.G.S.. Ractopamine levels on performance, carcass characteristics and quality of pig meat.

Revista Brasileira de Zootecnia (Online), v.42, p.325-333, 2013.

GUNAWAN, A.M.; RICHERT, B.T.; SCHINCKEL, A.P.; GRANT, A.L.; GERRARD, D.E. Ractopamine induces differential gene expression in porcine skeletal muscles. Journal of Animal Science, v.85, n.9, p.2115-2124, 2007.

KIEFER, C.; SANCHES, J.F. Metanálise dos níveis de ractopamina em dietas para suínos em terminação. Revista Brasileira de Zootecnia, v.38, n.6, p.1037-1044, 2009.

MARINHO, P.C.; FONTES, D.O.; SILVA, F.C.O.; SILVA, M.A.; PEREIRA, F.A.; AROUCA, C.L.C. Effects digestible lysine levels and of ractopamine on the performance and carcass characteristics of finishing barrows. Revista Brasileira de Zootecnia, v.36, n.6, p.1791-1798, 2007a.

MARINHO, P.C.; FONTES, D.O.; SILVA, F.C.O.; SILVA, M.A.; PEREIRA, F.A.; AROUCA, C.L.C. Effects of ractopamine and the methods of diet formulation on the porformance and carcass characteristics of finishing barrows. Revista Brasileira de p.533-539, 2009.

Zootecnia, v.36, n.4, p.1061-1068, $2007 b$.

MIMBS, K. J.; PRINGLE, T. D.; AZAIN, M. J.; MEERS, S. A.; ARMSTRONG, T. A. Effects of ractopamine on performance and composition of pigs phenotypically sorted into fat and lean groups. Journal of Animal Science, v.83, n.6, p.13611369, 2005.

MOODY, D.E.; HANCOCK, D.L.;

ANDERSON, D.B. Phenethanolamine repartitioning agents. In: MELLO, J.P.F.D. (Ed.). Farm animal metabolism and nutrition. New York: CAB, 2000. p.65-95.

MOORE, K.L.; DUNSHEA, F.R.; MULLAN, B.P.; HENNESSY, D.P.; D'SOUZA D.N. Ractopamine supplementation increases lean deposition in entire and immunocastratedd male pigs. Animal. Production. Science, v.49, n.12, p.1113-1119, 2009.

NATIONAL RESEARCH COUNCIL NRC. Nutrient requirements of beef cattle. 7th. rev. ed. Washington, DC: National Academies Press, 2000.

PEREIRA, F.A.; FONTES, D.O.; SILVA, F.C.O.; FERREIRA, W.M.; LANNA, A.M.Q.; CORRÊA, G.S.S.; SILVA, M.A.; MARINHO, P.C.; AROUCA, C.L.C.; SALUM, G.M. Efeitos da ractopamina e de dois níveis de lisina digestível na dieta sobre o desempenho e características de carcaça de leitoas em terminação. Arquivo Brasileiro de Medicina Veterinária e Zootecnia, v.60, n.4, p.943-952, 2008.

R DEVELOPMENT CORE TEAM. R: A language and environment for statistical computing. Vienna: $\mathrm{R}$ 
Rev. Bras. Saúde Prod. Anim., Salvador, v.16, n.3, p.582-590 jul./set.., 2015 http://www.rbspa.ufba.br ISSN 15199940

Foundation for Statistical Computing, 2010 .

SANCHES, J.F.; KIEFER, C.; MOURA, M.S.; SILVA, C.M.; LUZ, M.F.; CARRIJO, A.S. Níveis de ractopamina para suínos machos castrados em terminação e mantidos sob conforto térmico. Ciência Rural, v.40, n.2, p.403-408, 2010a.

SANCHES, J.F.; KIEFER, C.; CARRIJO, A.S.; MOURA, M.S.; SILVA, E.A.; SANTOS, A.P. Níveis de ractopamina para suínos machos castrados em terminação mantidos sob estresse por calor. Revista Brasileira de Zootecnia, v39, n7, p1523-1529, 2010 b.

STOLLER, G.M.; ZERBY, H.N.; MOELLER, S.J.; BAAS, T.J.; JOHNSON, C.; WATKINS, L.E. The effect of feeding ractopamina (Paylean) on muscle quality and sensory characteristics in three diverse genetic lines of swine. Journal of Animal Science, v.81, n.6, p.1508-1516, 2003.

UNIVERSIDADE FEDERAL DE VIÇOSA - UFV. Sistema de Análise Estatística e Genética - SAEG. Versão 9.1. Viçosa, MG, 2007.

WATKINS, L.E.; JONES, D.J.; MOWREY, D.H.; ANDERSON, D.B.; VEENHUIZEN, E.L. The effect of various levels of ractopamine hydrochloride on the performance and carcass characteristics of finishing swine. Journal of Animal Science, v.68, n.11, p.3588-3595, 1990.

WEBER, T.E.; RICHERT, B.T.; BELURY, M.A.; GU, Y.; ENRIGHT, K.; SCHINCKEL, A.P. Evaluation of the effects of dietary fat, conjugated linoleic acid, and ractopamine on growth performance, pork quality, and fatty acid prolifes genetically lean gilts. Journal of Animal Science, v.84, n.3, p.720-732, 2006

XIAO, R.J.; XU, Z.R.; CHEN, H.L. Effects of ractopamine at different dietary protein levels on growth performance and carcass characteristics in finishing pigs. Animal Feed Science and Technology, v.79, n.1, p.119-127, 1999.

Data de recebimento: $29 / 07 / 2014$

Data de aprovação: 13/08/2015 